\title{
Knowledge and awareness of the cause, prevention and control of cervical cancer amongst female undergraduates and faculty of health sciences: a cross sectional survey
}

\author{
Abhishek Tandon ${ }^{1}$, Snigdha Raja ${ }^{2 *}$, Mangala M. Pai ${ }^{3}$, B. Unnikrishnan ${ }^{4}$, Tanuj Kanchan ${ }^{5}$
}

${ }^{1}$ Department of Respiratory Medicine, Pt. B.D. Sharma PGIMS, Rohtak, Haryana, India

${ }^{2}$ Department of Cardiology, Krishna Institute of Medical Sciences, Hyderabad, Telangana, India

${ }^{3}$ Department of Anatomy, Kasturba Medical College, Mangalore, Karnataka, India

${ }^{4}$ Department of Community Medicine, Kasturba Medical College, Karnataka, India

${ }^{5}$ Department of Forensic Medicine and Toxicology, All India Institute of Medical Sciences, Jodhpur, Rajasthan, India

Received: 22 April 2019

Accepted: 13 June 2019

*Correspondence:

Dr. Snigdha Raja,

E-mail: snigdharaja.93@gmail.com

Copyright: $\odot$ the author(s), publisher and licensee Medip Academy. This is an open-access article distributed under the terms of the Creative Commons Attribution Non-Commercial License, which permits unrestricted non-commercial use, distribution, and reproduction in any medium, provided the original work is properly cited.

\begin{abstract}
Background: Carcinoma cervix is the second most common cancer in women worldwide, and the most common in India. In this study, the current knowledge of female undergraduates and faculty of health sciences regarding the various parameters like risk factors, symptoms, screening tests and vaccinations pertaining to cervical cancer was assessed.

Methods: A cross-sectional, self-administered anonymous questionnaire-based survey was carried out, in a medical college in Mangalore, which included 260 staff and students. Non random sampling was done and the study was carried out only after gaining institutional Ethical community approval and written informed consent from the subjects.

Results: Majority of the participants 185 (71.4\%) were aware that cervical cancer is one of the most wide- spread gynecological cancers in Asia. The awareness of causative agents of cervical cancer was known to $53.9 \%$ of the undergraduates and $50 \%$ of the faculty members. $73 \%$ of the total study groups have heard of HPV and around $68 \%$ agreed that it was detectable. $71 \%$ of the study sample had heard about the Pap smear test and $42 \%$ have undergone the test. The questions pertaining to the preventive measures of cervical cancer had good faculty preponderance with $91.8 \%$ giving a positive response. $84.1 \%$ of the students and $79.5 \%$ of the faculty members knew that abnormal vaginal bleeding was a symptom.

Conclusions: In this study an attempt has been made to study the correlates of knowledge of cervical cancer in a cohort which consisted of health care undergraduate and faculty. Majority of our study group was well aware of the various risk factors of cervical cancer and its preventable nature however awareness regarding the association between diets, multiple pregnancies and use of tobacco was poor.
\end{abstract}

Keywords: Cervical cancer, Carcinoma cervix, HPV

\section{INTRODUCTION}

India, with a population of 365.71 million has women aged between 15 years and above who stand at the risk of developing cervical cancer. The increasing risk of cervical cancer in women in India (aged 0-64 years) is $2.4 \%$ compared to $1.3 \%$ for the world. ${ }^{1} \mathrm{HPV}$ (human papilloma virus) is the main virus responsible for this 
sexually transmitted cancer. Risk factors include early onset of sexual activity, multiple sexual partners, high risk sexual partners, multiple pregnancies, prolonged use of birth control pills and use of tobacco in any form..$^{2-8}$ Experts agree that one of the most important things a women can do to reduce their risk of cervical cancer is to receive regular screening with a Pap test. Even though cervical cancer rates are higher among older women; cervical intraepithelial neoplasia (or CIN), the precursor lesion, most often occurs among younger women and therefore, screening younger women is an important strategy that can prevent cervical cancer from developing. A questionnaire based study by Joy $\mathrm{T}$ et al revealed that the awareness about the risk factors for cervical cancer among the educated youth in India, Sri Lanka and Nepal were $66 \%, 58.8 \%$ and $57.7 \%$ respectively. ${ }^{9}$ Saha et al conducted a study in Kolkata and reported a very low level of awareness among the graduate and postgraduate students about this important public health issue. ${ }^{10}$ Ali S et al have concluded that health professionals in Karachi, Pakistan have inadequate knowledge regarding cervical cancer and its screening. ${ }^{11}$ Pandey $\mathrm{D}$ et al have done a study on the awareness and attitude towards human papilloma virus vaccine among medical students, but then they have included both sex. ${ }^{12}$ The difference in our study population targeting the females in health science profession, both undergraduate students and faculty makes it unique.

\section{METHODS}

The study was set up in a health science institution in coastal Karnataka. A cross-sectional, self-administered anonymous questionnaire-based survey was carried out. The survey was conducted on female undergraduate students and faculty of MBBS, BDS and Nursing courses.

Only those who gave written consent were considered for the study. Doctors other than the faculty, and participants who refused to give written consent were excluded. Any female with the history of cervical cancer, and those rotating in Obstetrics/Gynecology were also excluded to avoid bias in the study.

The study was done within two months between May August 2012. With a relative precession of $10 \%$, confidence interval of $95 \%$ and power of $80 \%$ the sample size came to 235 medical students and staff members. Add $10 \%$ as non-responsive error and the final sample size came to be 260 . Non random sampling (convenience sampling).

The data was be collected using a semi structured, selfadministrated questionnaire which was divided into two main parts the first dealing with the socio-demographic profile of the subjects and second consisting of the questions regarding the knowledge and awareness about different aspects of cervical cancer. The study was carried out only after gaining institutional Ethical committee approval and written informed consent from the subjects.

\section{Statistical analysis}

It was done using SPSS (statistical package for social sciences) version 11. Statistical test chi square was done and $\mathrm{p}$ value less than 0.05 were considered statistically significant.

A total of 260 questionnaires were distributed after taking written informed consent to female undergraduate and faculty of health sciences and the responses were collected. One of the questionnaires did not have any response, was excluded from the study and so the final sample size was reduced to 259. The responses were subjected to statistical analysis using SPSS version 11.

\section{RESULTS}

Of the 259 subjects $124(47.9 \%)$ were less than 20 years of age, $96(37.1 \%)$ were between $20-30$ years, $22(8.5 \%)$ belonged to $30-40$ years and rest $17(6.6 \%)$ were above 40 years $165(64 \%)$ of the study group consisted of students and $94(36 \%)$ were faculty, both a mixture of medical, dental and nursing. When asked if they were aware that cervical cancer is one of the most wide- spread cancers among gynecological cancers in Asia (Question 1), $185(71.4 \%)$ gave a positive response, of them 129 were students and 56 were faculty.

A similar response from both the undergraduates and the faculty members was received regarding the awareness of causative agents of cervical cancer (Question 2) with $53.9 \%$ of the undergraduates and $50 \%$ of the faculty members giving positive responses and the comparison was not statistically significant. Of the total sample 'Yes' response was given by $136(52.5 \%)$ and 'No' response by $123(47.5 \%)$.

Questions (3, 5, 6, 7, 8, 9, 10, 11) pertaining to the different causative agents of cervical cancer were put up in the survey, $34.5 \%$ of the undergraduates and $35.1 \%$ of the faculty members said that they were aware that stress can produce cervical cancer, while $49.3 \%$ undergraduates and $49.4 \%$ faculty members said that poor hygiene was a causative agent. When asked about tobacco being a causative agent, $30.2 \%$ of the students and $37.2 \%$ of the faculty members gave a positive response.

Questions on whether multiple pregnancies ( $\mathrm{p}$ value 0.022 ) and pre mature sex (p value 0.010 ) can cause cervical cancer were statistically significant with $55.7 \%$ of the students and $37.2 \%$ of the faculty saying that multiple pregnancy was an important causative agent, while $58.5 \%$ of the students and $73.3 \%$ of the faculty said that pre mature sex can cause cervical cancer.

When asked to list out a few of the causative agents the answers were as following - smoking, using the same undergarment, excessive masturbation, poor hygiene. The faculty response was smoking in $71.6 \%$ and poor hygiene in $28.4 \%$. However the students listed using the same 
undergarment (39.6\%), smoking (27.5\%) and excessive masturbation $(25.3 \%)$ as the causative agent. This correlation was statistically significant.

When asked about the HPV $73 \%$ of the total study group said they have heard of it and around $68 \%$ agreed that it was detectable. $76.4 \%$ of the students and $67.5 \%$ of the faculty members said that they have heard about it, while $70.2 \%$ of the students and $65 \%$ of the faculty members knew that HPV was detectable. When asked further questions regarding the pap test and the frequency at which it needs to be repeated, $56 \%$ of the students and $73.2 \%$ of the faculty members said that 18 years is the right age to begin with the pap smear test and it should be repeated once every 3 years; $24 \%$ of the students and $14.1 \%$ of the faculty members said that correct age to begin with the pap smear test was 18 , but it should be repeated once every 4 years; $20 \%$ of the students and $12.7 \%$ of the faculty members said that the correct age to begin with the pap smear test was 20 and that it should be repeated once every 3 years.

There were questions pertaining to the preventive measures of cervical cancer like use of condoms, vaccine and Loop electrical excision procedure (LEEP). The answers had faculty preponderance with $69.6 \%, 76.7 \%$ and $91.8 \%$ respectively giving a positive response. However, statistical significance was derived in relation to LEEP awareness and use of condoms, but not for vaccines. When asked about the symptoms of cervical cancer, $84.1 \%$ of the students and $79.5 \%$ of the faculty members knew that abnormal vaginal bleeding was one of them.

\section{DISCUSSION}

Awareness regarding cervical cancer and its prevention is quite low amongst Indian women. In our study it was found out that $71.4 \%$ of the total respondents were aware that cervical cancer is the most wide spread gynecological cancer in Asia, which is better than responses in a previous study in which only $24 \%$ of the total respondents were aware of this fact. ${ }^{11}$ At one end of the spectrum is the high awareness (86\%) in Cameroonian nursing staff and at the other end is the study report based in Kolkata were $84 \%$ had no awareness regarding this major gynecological problem. ${ }^{13-}$ ${ }^{14}$ In this study out of the $71.4 \%$, it was found out that the awareness was better in students $(78.2 \%)$ than in the faculty members $(50.6 \%)$. A similar response from both the undergraduates and the faculty members was received regarding the awareness of causative agents of cervical cancer with $52.5 \%$ of the total sample giving positive responses. $34.5 \%$ of the undergraduates and $35.1 \%$ of the faculty members said that they were aware that stress can produce cervical cancer, as compared to $0.12 \%$ of the respondents in a previous study, which shows better awareness among this study group. ${ }^{9} \quad 49.3 \%$ undergraduates and $49.4 \%$ faculty members were aware that poor hygiene was a causative agent, showing much more awareness when compared to results of a previous study which shows that $16 \%$ of the sample was of the opinion that poor hygiene can be a risk factor for cervical cancer. ${ }^{11}$

When asked about tobacco being a causative agent, $30.2 \%$ of the students and $37.2 \%$ of the faculty members gave a positive response, which again shows better awareness when compared to a previous study which shows $7 \%$ awareness among the respondents. ${ }^{11}$

Cervical cancer is strongly associated with sexual behavior, and the risk increases with the multiple partners, early age at first intercourse, increasing parity, and smoking. ${ }^{15}$ Having multiple sex partners as a causative factor of was known by $81.9 \%$ of the undergraduates and $80.5 \%$ of the faculty members, which was much more than observed in a previous study where awareness was only $11.5 \% .{ }^{16} 40.3 \%$ of the students and $44.7 \%$ of the faculty members said that they knew that excessive use of birth control pills can lead to cervical cancer which shows that the respondents of this study are better aware than the study which shows awareness about use of birth control pills causing cervical cancer being 28.4\% (Indian), $42.5 \%$ (Nepali) and 39.2\% (Sri Lankan). ${ }^{9}$ There is a high risk of cervical intraepithelial neoplasia and cervical cancer in the women who are under long term use of contraceptives.

In our study, indulging in premature sex as a cause for cervical cancer was known by 144 (55.6\%) of the respondents. A Kolkata based study by Shah et al reported $41 \%$ awareness regarding sexual activity and its relation with cervix cancer. ${ }^{10}$ Joy $\mathrm{T}$ et a concluded that the educated youth had less knowledge of risk factors, such as HPV, sex at an early age, sex with multiple partners, use of birth control measures, low consumption of fruits/vegetables and stress which can also cause cervix cancer. ${ }^{19}$

When asked about the HPV $73 \%$ of the total study group said they have heard of it and $68 \%$ agreed that it was detectable which is better than a similar study, where the awareness of human papillomavirus (HPV) was found to be $48.9 \%, 52.5 \%$ and $48.5 \%$ respectively in India, Nepal and Sri Lanka. ${ }^{9}$

In our study $184(71 \%)$ of the respondents had heard about the pap smear test and 109 (42\%) had undergone the test, when compared to a similar study where out of 69 respondents, $61(88.4 \%)$ had knowledge regarding Pap test as one of the preventive measures and of 61 staff nurses who knew about Pap test, only five $(8 \%)$ had undergone Pap test. In a similar study undertaken by Ekta Singh et al, $74 \%$ of the respondents were aware of Pap test but only $11 \%$ had undergone this test. ${ }^{14}$

In another study, $95 \%$ of the study population were not aware of Pap test. ${ }^{17}$ On the other hand $84 \%$ of the study sample of Mc Carey et al study were aware of this test. ${ }^{13}$ 
These reports indicates a variable spectrum of study groups and their knowledge regarding this aspect of carcinoma cervix.

With respect to the right age to begin with the pap test and the frequency at which it needs to be repeated, $56 \%$ of the students and $73.2 \%$ of the faculty members said that 18 years is the right age to begin with the pap smear test and it should be repeated once every 3 years and $24 \%$ of the students and $14.1 \%$ of the faculty members said that correct age to begin with the pap smear test was 18 , but it should be repeated once every 4 years. Most of the Cancer Societies, Institutes and Medical Associations, recommend that annual Pap testing should begin at the onset of sexual activity or at age 18, repeated annually and after 3 annual tests have been normal, less frequently at the discretion of the doctor and patient. Women who are past menopause need to have regular Pap tests, however, those who have undergone a hysterectomy with removal of cervix do not require Pap testing, unless the surgery was performed to treat cervical cancer or its precursors. So majority was aware regarding the right age of onset of Pap test but not regarding the frequency at which this test needs to be repeated.

The preventive measures of cervical cancer are use of condoms, vaccine and Loop electrical excision procedure (LEEP). The awareness regarding these in our faculty was $69.6 \%, 76.7 \%$ and $91.8 \%$, and that of the group as a whole was around $60 \%, 70 \%$ and $63 \%$ respectively and when compared to previous study this study group shows much more awareness. The awareness regarding HPV vaccine in Ali $\mathrm{S}$ et al was $1 \%$, Singh E et al was $18 \%$, a study based in Belgium was $50 \%$ and in another study in India by Pandey D was $75.6 \% .{ }^{18}$ Chelimo $\mathrm{C}$ et al are of the impression that their participants, undergraduates in health care, who knew someone ever diagnosed with cervical cancer were more likely to have heard of the HPV vaccine. ${ }^{19}$

It has been revealed that condoms may not prevent HPV infection, but may protect against genital warts, CIN II OR III and ICC. ${ }^{20}$ However avoiding direct contact with HPV is deemed to be an effective means of reducing the risk of HPV transmission and consistent and correct use of latex condoms provides some protection against it. ${ }^{21}$ The women involved in this study have a medical curriculum that addresses HPV risk, cervical cancer prevention and control, HPV vaccination, and condoms.

$60.7 \%$ of the students and $62.5 \%$ of the faculty members said that cervical cancer can be transmitted via blood. Cervical cancer cannot be transmitted via blood and so there is a misconception regarding this risk factor and needs to be addressed.

The sexual behaviors specifically associated with greater risk are intercourse at an early age, multiple male sexual partners, and sex with a male partner who has had multiple sexual partners. Ali SF et al report that their study population most of the health professionals stated, unsafe sexual practices, infection, early onset of sexual practice, as common risk factors which is in accordance with their literature search, however poor hygiene, family history and null parity as risk factors were some of the misconceptions present. ${ }^{11}$

Only $17.1 \%$ of the students and $21.1 \%$ of the faculty members thought that cervical cancer was a genetic disease when compared to a similar study which reports $31.8 \%$ (Indians), $0.2 \%$ (Nepali) and $20.8 \%$ (Sri Lankan) that gave a positive response. ${ }^{9}$ A report by Patrik 2000 says that genetic epidemiological studies show that genetic factors contribute individual significant risk to develop this virally induced cervical cancer. ${ }^{22}$ de Zelmanowicz et al, 2004 derived an association between invasive cervical cancer and its relationship between 1st degree relative (mother, sister, daughter). ${ }^{23}$ They further state that risks appear to be stronger among full blood relatives compared to half-blood /adoptive relatives.

When our cohort was asked about the symptoms of cervical cancer, $84.1 \%$ of the students and $79.5 \%$ of the faculty members replied that abnormal vaginal bleeding was a symptom.

\section{CONCLUSION}

Cervical cancer is said to be prevented in two ways: (i) primary prevention, by preventing or neutralizing the infection with human papillomavirus (HPV), for example through prophylactic HPV vaccination, and (ii) secondary prevention, aimed at preventing precancerous lesions from progressing to invasive cancer through screening, early detection, diagnosis, and treatment. This survey indicated that the knowledge about the association between HPV and cervical cancer and Pap smear test was high but not all had undergone this test.

Women could benefit greatly from educational interventions to encourage primary and secondary cervical cancer prevention programs. In addition to providing adolescents with clear and meaningful information about the implications of HPV infection and conducting more awareness campaigns at universities' campuses, health education activities should focus on educating the health professionals, the risk factors and early warning signs of this cancer. Health education should also focus on the role of safe sex behavior by condom usage and limiting the number of sexual partners to curtail the spread of HPV and also on encouraging the participation in regular cervical screenings, thus reducing the incidence of cervical cancer. This study highlights the need of Continuing Medical Education program at the hospital level since health care professionals in general and faculty in particular if properly aware of this disease can educate the general masses. It is only and only through proper health education of health science personnel that the burden of cervical cancer can be reduced. 
Funding: No funding sources

Conflict of interest: None declared

Ethical approval: The study was approved by the Institutional Ethics Committee

\section{REFERENCES}

1. Consolidated report of hospital based cancer registries 2001-3, national cancer registry program. New Delhi: Indian Council of Medical Research; 2007. Available at: http://ncdirindia.org/NCRP/ Annual_Reports.aspx. Assessed 18 October 2012.

2. Goldsmith MR, Bankhead CR, Kehoe ST, Marsh G, Austoker J. Information and cervical screening: a qualitative study of women's awareness, understanding and information needs about HPV. J Med Screen. 2007;14:29-33.

3. Pitts M, Clarke T. Human papillomavirus infections and risks of cervical cancer: what do women know? Health Educ Res. 2002;17:706-14.

4. Castellsague X, Bosch FX, Munoz N, Meijer CJ, Shah KV. Male circumcision, penile human papillomavirus infection, and cervical cancer in female partners. N Engl J Med. 2002;346:1105-12.

5. Castle PE, Wacholder S, Lorincz AT, Scott DR, Sherman ME. A prospective study of high-grade cervical neoplasia risk among human papillomavirus-infected women. J Natl Cancer Inst. 2002;94:1406-14.

6. Appleby P, Beral V, Berrington de Gonzalez A, Colin D, Franceschi S, et al. Carcinoma of the cervix and tobacco smoking: collaborative reanalysis of individual data on 13,541 women with carcinoma of the cervix and 23,017 women without carcinoma of the cervix from 23 epidemiological studies. Int J Cancer. 2006;118:1481-95.

7. Munoz N, Franceschi S, Bosetti C, Moreno V, Herrero R. Role of parity and human papillomavirus in cervical cancer: the IARC multicentric casecontrol study. Lancet. 2002;359:1093-101.

8. Appleby P, Beral V, Berrington de Gonzalez A, Colin D, Franceschi S. Cervical cancer and hormonal contraceptives: collaborative reanalysis of individual data for 16,573 women with cervical cancer and 35,509 women without cervical cancer from 24 epidemiological studies. Lancet. 2007;370:1609-21.

9. Joy T, Sathian B, Bhattaria C, Chacko J. Awareness of cervix cancer risk factors in educated youth: A cross-secional, questionnaire based survey in India, Nepal and Srilanka. Asian Pacific J Cancer Prevent. 2011;12:1707-12.

10. Saha A, Nag Chaudhury A, Bhowmik P, Chatterjee R. Awareness of cervical cancer among female students of premier colleges in Kolkata, India. Asian Pacific J Cancer Prevent. 2010;11:1085-90.

11. Ali SF, Ayub S, Manzoor NF, Azim S, Afif M. Knowledge and awareness about cervical cancer and its prevention amongst interns and nursing staff in tertiary care hospitals in Karachi, Pakistan. PLoS ONE. 2010;5(6):e11059.
12. Pandey D, Vanya V, Bhagat S, Binu VS, Shetty J. Awareness and Attitude towards Human Papillomavirus (HPV) Vaccine among Medical Students in a Premier Medical School in India. PLoS One. 2012;7(7):e40619.

13. Catherine Mc C, David P, Pierre MT, Michel B, Anderson SD, Patrick P. Awareness of HPV and cervical cancer prevention among Cameroonian healthcare workers. BMC Women's Health. 2011;11:45.

14. Singh E, Seth S, Rani V, Srivastava DK. Awareness of cervical cancer screening among nursing staff in a tertiary institution of rural India. J Gynecol Oncol. 2012;23(3):141-6.

15. Burkett BJ, Peterson CM, Birch LM. The relationship between contraceptives, sexual practices and cervical human papillomavirus infection among a college population. $J$ Clin Epidemiol. 1992;45:1295-302.

16. Shah V, Vyas S, Singh A, Shrivastava M. Awareness and knowledge of cervical cancer and its prevention among the nursing staff of a tertiary health institute in Ahmedabad, Gujarat, India; 2012.

17. Roy B, Tang TS. Cervical cancer screening in Kolkata, India: Beliefs and predictors of cervical cancer screening among women attending a women's health clinic in Kolkata, India. J Cancer Educ. 2008;23:253-59.

18. Donders GG, Gabrovska M, Bellen G, Van Keirsbilck J, Van Den Bosch T. Knowledge of cervix cancer, human papilloma virus (HPV) and HPV vaccination at the moment of introduction of the vaccine in women in Belgium. Arch Gynecol Obstet. 2008;277:291-8.

19. Chelimo C, Wouldes TA. Human papillomavirus knowledge and awareness among undergraduates in healthcare training in New Zealand; 2008. Available at: https://www.ncbi.nlm.nih.gov/pubmed/19859090. Assessed on 20th October 2012.

20. Manhart LE, Koutsky LA. Do condoms prevent genital HPV infection, external genital warts, or cervical neoplasia? A meta-analysis. Sex Transm Dis. 2002;29:725-35.

21. Sandra Millon Underwood, Edith Ramsay-Johnson, Lois Browne, Natasha Caines, Ashanti Dean, Samantha Duval, et al. What Women in the United States Virgin Islands Still Want and Need to Know About HPV, Cervical Cancer, and Condom Use. J Natl Black Nurses Assoc. 2010;21(1):25-32.

22. Patrik KE Magnusson MSc, Postgraduate Student and Ulf B. Gyllensten PhD, Professor Section for Medical Genetics, Department of Genetics and Pathology, Rudbeck Laboratory, Uppsala University, S-751 85 Uppsala, Sweden Available online 4 April 2000. Available at: https://www.researchgate.net/ publication/51839375_Awareness_of_Cervix_Cance r_Risk_Factors_in_Educated_Youth_A_CrossSectional_Questionnaire_Based_Survey_in_India_N epal_and_Sri_Lanka. Assessed on 20th October 2012. 
23. de Zelmanowicz MA, Hildesheim A. Family history of cancer as a risk factor for cervical carcinoma: a review of the literature. Papillomavirus Report. 2004;15(3):113-20.
Cite this article as: Tandon A, Raja S, Pai MM, Unnikrishnan B, Kanchan T. Knowledge and awareness of the cause, prevention and control of cervical cancer amongst female undergraduates and faculty of health sciences: a cross sectional survey. Int J Reprod Contracept Obstet Gynecol 2019;8:2732-7. 